\title{
Constructing a Coactivation Model for Explaining Humor Elicitation
}

\author{
Ryota Nomura, Shunichi Maruno \\ Human-Environment Studies, Kyushu University, Fukuoka, Japan. \\ Email: nomuraryota@gmail.com \\ Received May $1^{\text {st }}$, 2011; revised June $13^{\text {th }}$, 2011; accepted July $24^{\text {th }}, 2011$.
}

\begin{abstract}
The present study first aimed to construct a coactivation model that integrates cognitive and motivational variables that determine an individual's conscious humor experience. It then aimed to test the model's reliability, validity, and generalizability. As part of the study, 16 (out of 48) four-frame cartoons were randomly presented to 201 (42 male and 159 female) high school students and 302 (185 male and 117 female) undergraduate and graduate students (age range was 15 to $23, M=18.15, S D=1.79$ ) who were instructed to rate items related to the variable humor. Using structural equation modeling (SEM), the generalizability of the model to predict the humor experience to a great extent within different population samples was shown. Furthermore, the theoretical prediction of the coactivation model was supported. The results are discussed from the viewpoint of future research that could demonstrate the possible application of the coactivation model.
\end{abstract}

Keywords: Humor Experience, Coactivation Model, Dynamical Comprehension and Elaboration Theory (DCET)

\section{Constructing a Coactivation Model for Explaining Humor Elicitation}

Owing to its potential effect on physical and mental health, humor has recently begun to receive attention in several fields, especially in medical and health care. Since humor as a mechanism can produce such effects, the possibility of conscious positive emotions affecting human beings physiologically has been pointed out by researchers (Martin, 2007). It is suggested that emotional experiences affect the human immune function mediated by the brain's immune system. Regarding positive emotions, a study dealing with type II diabetes patients demonstrated that brain endorphin produced as a result of experiencing humor can reduce the increase in the blood glucose level (Hayashi et al., 2003). This study suggests the importance of conscious humor experience with certain qualities of "I'm amused" or "I'm overwhelmed by laughter" as well as an effect of the exercise of smiling or laughing. This leads to the viewpoint that the conditions of humor elicitation and the degree of conscious humor experience are both key problems. We focus in particular on a cognitive-perceptual process and a subsequent emotional response of humor (Martin, 2007: p. 5). In this study, we use the term humor to refer to a temporal, pleasant emotion such as exhilaration (Ruch, 1993) or mirth (Martin, 2007), elicited by certain trigger stimuli, including words and actions expressed by another person or oneself (Nomura \& Maruno, 2008b). Unless otherwise noted, the term humor indicates not an emotional state but a conscious emotional experience. In addition, we differentiate humor itself from humor stimuli, which refer to trigger behaviors or their representations (e.g., cartoons and texts).

Some existing research has pointed out that the determinants of one's humor experience are cognitive variables relevant to information processing about a humor stimulus (e.g., ease of understanding and elaboration, Wyer \& Collins, 1992) and motivational variables involved in the contents of the stimulus (e.g., aggression, Zillmann, Bryant, \& Cantor, 1974). These variables must have interaction effects on one's humor experience, because humor is elicited by the fact that a person allocates attention to a humor stimulus and processes information about it. Nevertheless, in existing studies regarding humor processing, the variables are controlled separately. Consequently, the interrelationship between cognitive and motivational variables is not clear. The purpose of the current study is to propose a coactivation model that integrates cognitive and motivational variables to explain the humor elicitation process more adequately, and to examine the reliability and validity of the model.

However, existing theories involve the following problem: they have been confusing the conditions of humor elicitation with the determinants of the humor experience. We first identify the conditions of humor elicitation. Second, we briefly review the studies dealing with cognitive and motivational variables that determine one's humor experience. Third, we will examine the interrelationship between the variables.

\section{The Conditions of Humor Elicitation}

Currently, the incongruity theory, which focuses on information processing about a humor stimulus, is regarded as the most prevalent theory explaining humor elicitation (Forabosco, 2008; Ito, 2007), despite some counterarguments (e.g., Ferro-Luzzi, 1997). There are two distinct positions within the incongruity theory. One is the narrow incongruity theory (incongruity model) that argues that incongruity itself is a sufficient condition to elicit humor (Nerhardt, 1970). The other is the incongruity and resolution theory (incongruity-resolution model) that advocates that some resolution of incongruity is necessary (Shultz, 1972; Suls, 1972). In this connection, the term incon- 
gruity refers to a type of strangeness derived from the combination of two distinct concepts-which usually exist in rather different contexts - into one situation (bi-sociation, Koestler, 1964; also see Hilson \& Martin, 1994), or deviation from schema-based anticipation or an expected pattern (Deckers, 1993; Nerhardt, 1970).

On the other hand, the term resolution of incongruity means finding a series of schema that explains the incongruous situation. Typically, the process involves voluntary inference about an unmentioned aspect of the situation. For example, consider the following joke:

1) "Is the doctor at home?" the patient asked in his bronchial whisper. 2) "No," the doctor's young and pretty wife whispered in reply. "Come right in." (Raskin, 1985: p. 100; the numbers have been added by us).

Viewed from the perspective of a situation model (Zwaan \& Rapp, 2006), a typical comprehension process of story-based humor stimuli is as follows: when a person reads the first sentence, they anticipate the typical "doctor" script-namely, that the man has come in order to seek treatment. However, the reply "No, come right in" cannot be interpreted under the "doctor" situation. This leads the reader to infer the unmentioned part of the context. Consequently, the reader reinterprets the situation as a "lover" script, wherein the patient has come for a secret liaison with the doctor's young and pretty wife (Martin, 2007: pp. 90-91; Ruch, 2008: p. 25).

The incongruity-resolution model has been generally accepted because by adopting the concept of resolution, it can probabilistically explain more humor phenomena than the incongruity model (Ito, 2007). However, there exist humor stimuli that lack a clear resolution-for instance, incongruity in the psychophysical task known as the weight-judgment paradigm (Deckers, 1993). The incongruity-resolution model cannot explain these stimuli. On the other hand, the incongruity model is inadequate as it fails to explain the phenomenon wherein humor is not experienced until one resolves the incongruity.

Recently, Ito (2007) proposed the sentient and logical incongruity (SLI) model that offers a solution to the incongruity or incongruity-resolution problem by discriminating between two types of incongruity. According to the SLI model, the incongruity of a humor stimulus is resolved not because "the facts are different from those anticipated" as assumed by existing theories; rather, it is because a reader cannot understand the logical consistency of the story line. Consequently, the purpose of the resolution is not to match the facts to those anticipated, but to find some logical consistency. For example, a reader of the above mentioned "doctor" joke would infer the unmentioned "lover" interpretation. This is because they merely try to find a logical consistency in the story line and not to fit an anticipated utterance with the actual utterance. The most important thing is that a reader finds the utterance strange even when they correctly understand its intention. If the reader finds no "strangeness," humor cannot be elicited. In other words, the condition for humor elicitation is not logical incongruity as a lack of logical consistency but sentient incongruity as a deviation from anticipation or common sense, which prompts a feeling that "the stimulus is strange." This leads to the view that all humor stimuli contain sentient incongruity as the condition of humor elicitation; however, only some humor stimuli contain logical incongruity. According to Ito (2007), since logical in- congruity may disrupt one’s mental model (Johnson-Laird, 1980 ) or threaten the coherency of the real world, a reader has to resolve it as quickly as possible at that time. The reader's cognitive resources are occupied by the effort, leading to the lack of a humor experience until logical incongruity is resolved (see Figure 1). However, such processing should be performed in a "playful" situation (Forabosco, 2008). Apter's (1982) Reversal Theory also suggests that humor is elicited when one is in a "paratelic" (i.e., playful) state of mind. This is because no humor is elicited when a subject determines a situation is dangerous and is disposed to make a fight-or-flight response immediately (Lazarus, 1991).

Typically, logical incongruity is found in humor stimuli with a story line because one can find inconsistency in a logical flow of events only when the stimuli have a story line in which the contents (time, space, the intention of the protagonist, etc.) are constrained by the course of the story (Zwaan \& Rapp, 2006). However, this does not mean that reinterpreted situations should be typical ones. For example, consider the following riddle (Zwaan \& Rapp, 2006: p. 725).

Question: "How do you get an elephant into a refrigerator?"

Answer: "You open the fridge, put the elephant inside, and close the door."

The answer provides only a partial resolution of incongruity leaving some element of incongruity remaining because refrigerators are normally not big enough to keep an elephant in. Rothbart and Pien (1977) suggested distinguishing between possible incongruity and impossible incongruity. Possible incongruity is reinterpreted in accordance with our common mental models of the world. On the other hand, impossible incongruity can be reinterpreted but the situation is somewhat strange in the light of the real-world. Similarly, McGhee, Ruch, \& Hehl (1990: p. 124) defined nonsense jokes as jokes for which the "punch line may 1) provide no resolution at all, 2) provide a partial resolution (leaving an essential part of the incongruity unresolved), or 3) actually create new absurdities or incongruities.” According to Forabosco (2008), unlike other kinds of problem-solving, some residual incongruities are left in humor processing regardless of whether or not incongruities are reinterpreted adequately in the light of normal mental models. Based on this, several theorists have thought that humor experience elicited by nonsense jokes is explained by the incongruity-resolution model with a few modifications (e.g., Forabosco, 2008; Ruch, 2008). In contrast, Ito's (2007) SLI model assumes that the residual incongruity is innately derived from the strangeness (sentient incongruity) provided by the

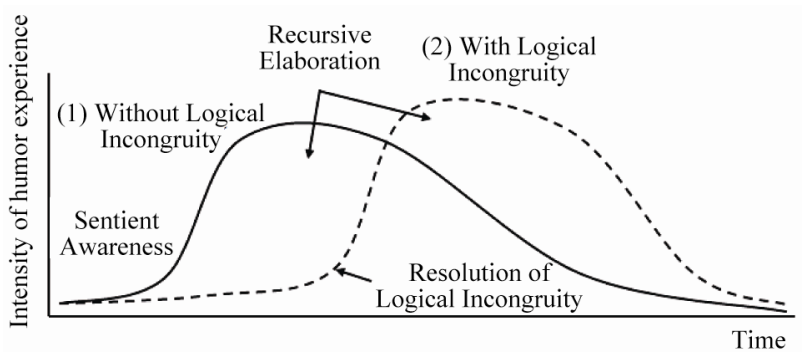

Figure 1.

A framework of dynamical comprehension and elaboration theory. The continuous and dashed lines show a process for humor stimuli with and without logical incongruity, respectively. 
juxtaposition of opposite concepts or deviation from an expected pattern while logical inconsistency (logical incongruity) is not relevant. That is, the SLI model is a new incongruity model that specifically advocates that the essential condition of humor is sentient incongruity. The hypothesis that sentient incongruity must be the essential condition for humor experience corresponds with the developmental course of humor appreciation (Shultz, 1972) and proto-humor of apes (Gervais \& Wilson, 2005).

Focusing on sentient incongruity, the SLI model makes it possible for researchers to study humor experience regardless of the specific topic, content or form (e.g., story-based cartoons or nonverbal behavior in everyday conversation) of stimuli. In this study, we will propose an integrative model based in essence on the SLI model.

\section{The Determinants of the Humor Experience}

Cognitive variables: Ease of understanding and amount of elaboration

Wyer and Collins (1992) proposed the comprehensionelaboration theory that predicts the extent of humor experience, focusing on the cognitive process of humor elicitation. Since this theory is based on the incongruity and resolution model, comprehension implies information processing from the perception of incongruity to the finding of an unmentioned alternative concept (resolution of incongruity). Elaboration, in contrast, means an inference about the features of a given humor stimulus that is not always necessary for comprehension. For instance, elaboration includes imagining happenings that occurred in the past or that will occur in the future and remembering some past events that the reader actually experienced.

In addition, the comprehension-elaboration theory assumes two cognitive variables that determine humor experience: difficulty in understanding and extent of elaboration (Wyer \& Collins, 1992), both of which are assumed to be time variables. Difficulty in understanding is the time course until a reader finds an alternative concept. According to Wyer and Collins (1992), this variable has an inverted U-shaped relationship with humor experience (i.e., the humor experience is lower when the difficulty is too small or too large, and the highest when the difficulty is of a moderate level). Amount of elaboration, in contrast, is the amount of time spent on elaboration after comprehension. This variable is assumed to be proportional to humor experience (i.e., humor experience is higher when the amount of elaboration is larger). Wyer and Collins (1992) postulate that the time allocation between these two variables determines actual humor experience, because a reader does not spend any more than a specified amount of time on each stimulus.

Although the comprehension-elaboration theory can explain a larger number of humor stimuli by adopting cognitive variables, it involves the following two problems. First, the theory is completely based on the incongruity and resolution model (Wyer \& Collins, 1992, p. 665). As long as the theory is based on the incongruity-resolution model, it cannot explain humor elicitation by a stimulus without clear resolution, such as nonsense humor. Second, subsequent empirical studies have demonstrated that the original assumption of an inverted U-shaped relationship is not supported. Rather, there is a simple proportional relationship, indicating that the easier it is to understand a humor stimulus, the funnier it is (Cunningham \& Derks, 2005).

To resolve both the problems, Nomura and Maruno (2008b) expanded the theory and proposed the dynamical comprehension-elaboration theory (DCET). DCET is based on the SLI model in terms of the conditions of humor elicitation. Moreover, DCET reconceptualizes the comprehension and elaboration process as follows. Although a humor stimulus always contains sentient incongruity, it does not always contain logical incongruity (Ito, 2007). To find a stimulus funny, a reader has to perceive sentient incongruity as the sufficient condition, regardless of whether or not the stimulus contains logical incongruity. This process is called the sentient awareness process, in the sense that one feels that the stimulus with sentient incongruity is "strange" whereas one's own recognition is normal.

Initially, elaboration was assumed as a pervasive process for imagining happenings or remembering one's experiences (Wyer \& Collins, 1992). However, Nomura and Maruno (2008b) have slightly modified the concept of the elaboration process. According to them, once a reader imagines happenings triggered by the awareness of sentient incongruity, they re-represent or reexamine the humor stimulus from the new point of view. Besides, the re-representation of the humor stimulus induces the reader to engage in further sequential imagining and remembering (see Figure 1). This phase is called the recursive elaboration process because it indicates a cyclic representational operation between imagining or remembering happenings and the re-representation of a humor stimulus. In DCET, the time for recursive elaboration is the only determinant, and it is proportional to the degree of humor experience.

Such reconceptualizations make it possible for DCET to explain the humor experience elicited by a stimulus without resolution (i.e., a stimulus that contains only sentient incongruity). On the basis of DCET, Nomura and Maruno (2008b) deductively concluded that a humor stimulus is funnier when it is easier to understand. First, if a reader cannot perceive sentient incongruity, they never progress to the elaboration process. Second, if a humor stimulus also contains logical incongruity, a reader's cognitive resources are occupied with the task of finding logical consistency until the incongruity is resolved, thereby blocking the humor experience. Thus, sentient awareness and the resolution of logical incongruity, if any, are the prerequisites for recursive elaboration. Consequently, the easier it is to become aware of sentient incongruity and resolve logical incongruity, the greater is the amount of time that an individual can spend on recursive elaboration. This in turn results in a proportional increase in the humor experience.

An empirical study (Nomura \& Maruno, 2008a) dealing with Rakugo (a traditional Japanese storytelling performance) as humor stimuli confirmed the postulations of DCET by using structural equation modeling (SEM). The study showed that ease of understanding and amount of elaboration predict humor experience, and that the validity of the postulations can be demonstrated by using multiple group SEM analyses. These results support the conclusion that ease of understanding and amount of elaboration are determinants.

Motivational variables: Aversiveness and arousal level

The superiority, disparagement, and hostility theories are repeatedly mentioned in explanations of humor elicitation (Morreall, 1987). These theories generally postulate that some characteristics of a humor stimulus, such as discriminatory, 
hostile, and so-called tendentious (aggressive and sexual) contents, are the conditions for humor elicitation or at least increase the humor experience (Ferguson \& Ford, 2008). However, some humor stimuli, such as a simple pun, do not appear to possess these characteristics. Therefore, it cannot be concluded that contents are a necessary condition for humor elicitation. Rather, these must be the determinants of the degree of humor experience. Some empirical studies have suggested that contents that may violate social norms and threaten psychological safety (aversiveness) enhance an individual's humor experience. For example, McCauley, Woods, Coolidge, and Kulick (1983) showed that funniness is positively correlated with ratings for aggression by the other participants $(r=.49$ to .90).

It has been assumed that aversiveness affects one's humor experience because the contents raise a person's arousal level. This assumption is largely based on the fact that as compared to neutral subjects, high-arousal subjects gain greater humor experience. Schachter and Wheeler (1962) compared responses to comedy and subjective rating scores for a comedy movie between three groups: a group that was administered epinephrine, which raises arousal level; a group that was administered chlorpromazine, which reduces arousal level; and a group that was administered a placebo, which has no effect on arousal level (control group). According to the results, as compared to the control group, the group that was administered epinephrine smiled and laughed more frequently, and showed higher subjective rating scores. On the other hand, the group that was administered chlorpromazine smiled and laughed less frequently as compared to the control group, and also showed lower subjective rating scores. These results indicate that arousal level is proportional to the humor experience and suggest the "transfer of excitation effect" (Cantor, Bryant, \& Zillmann, 1974), in which the raised arousal level is reflected in the humor experience.

In addition to the transfer of excitation effect, the possibility of an "arousal boosting effect" (Martin, 2007: p. 76) in which the contents of the humor stimulus per se raise one's arousal level is pointed out. Several studies using physiological indices such as skin conductance or heart rate have consistently revealed that the autonomic nervous system is activated and arousal level is raised when an individual is exposed to a humor stimulus (Averill, 1969; Chapman, 1973; Goldstein, Harman, McGhee, \& Karasik, 1975). Moreover, Langevin and Day (1972) demonstrated that the more cartoons increased skin conductance and heart rate, the higher was an individual's rating score. This result suggests that humor stimuli themselves raise one's arousal level, leading to a high subjective rating.

However, although aversiveness also raises an individual's arousal level, it is not clear if the arousal-raising effect of aversiveness consistently leads to an increase in the humor experience. For instance, Zillmann and his colleagues (Zillmann, Bryant, \& Cantor, 1974) revealed an inverted U-shaped relationship between the hostile or aggressive nature of humor stimuli and their funniness ratings (i.e., moderate hostility is rated the funniest). In addition, although a study dealing with sick humor also referred to an inverted U-shaped relationship between "sickness" and funniness (Herzog \& Karafa, 1998), subsequent studies did not support the relationship and instead indicated a negative correlation in female participants and no effect in males (Herzog \& Anderson, 2000; Herzog, Harris,
Kropscott, \& Fuller, 2006).

As described above, aversiveness seems to increase the humor experience in some cases; however, in others, it has no effect or rather, seems to decrease the humor experience. These results are not found if the aversiveness involved in a humor stimulus raises the arousal level and increases the subjective humor experience consistently through a certain way of affecting the information processing (e.g., allocation of cognitive resources such as attention) of humor elicitation. How, then, does aversiveness function when it increases one's humor experience?

\section{Coactivation Model of Elaboration}

\section{Proposal of Coactivation model (Integrative model)}

We will now propose a model that integrates cognitive and motivational variables in order to explain the mechanism of aversiveness that affects the humor experience. The integrative model, in short, hypothesizes that elaboration affects aversiveness as well as the humor experience. In other words, this model assumes that an apparent predictive power is observed because both aversiveness and humor are influenced by the use of elaboration as a third variable (see Figure 2).

In most cases, the aversive contents of a humor stimulus are implied by using some format of jokes or cartoons rather than direct references. Owing to this, during the elaboration process, making an inference about the humor stimulus mainly involves an understanding of the implied aversive content. As a result of recursive elaboration with the imagining and remembering of relative situations, aversive conceptions as well as the humor experience are activated and stored in the short-term memory. Since individuals often recognize the aversive conceptions within the humor experience, aversiveness is viewed as the cause of the humor experience. However, aversive conceptions themselves are activated as a result of the simultaneous recursive elaboration process of humor elicitation. It is in this context that we refer to the integrative model as the coactivation model.

On the basis of the coactivation model, as the amount of elaboration (and also ease of understanding) has direct predictive power, we can hypothesize that the apparent predictive power decreases when the effect of elaboration is removed. If the hypothesis is right, we can explain the phenomenon that aversiveness seems to increase the humor experience in some cases and seems to decrease it in others. That is, the coactivation model predicts that aversiveness appears to have an effect on the humor experience only in the case in which a considerable amount of elaboration is provoked depending on the characteristics of the humor stimulus, although the actual effect of aversiveness is weak. The present study aims to construct a coactivation model that integrates cognitive and motivational

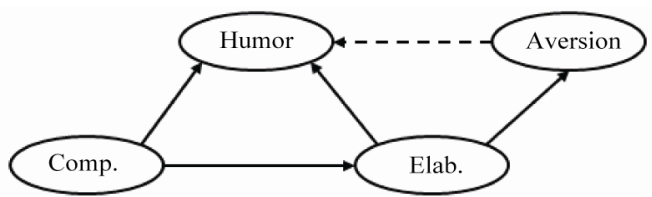

Figure 2 .

The basic structure of the coactivation model. The dashed arrow represents a relatively lower coefficient when the coactivation (i.e., simultaneous arousing) effect of Elab. is taken into account. Comp. = Comprehension, Elab. $=$ Elaboration. 
variables and to investigate the generalizabilities and validities of the model.

\section{Method}

\section{Participants}

The sample obtained from 201 (42 male and 159 female) high school students and 302 (185 male and 117 female) undergraduate and graduate students. They were between 15 to 23 years of age $(M=18.15, S D=1.79)$.

\section{Humor Stimuli}

The humor stimuli were 48 four-frame cartoons created by the same author. This form is very common and popular in Japan. Typically, the first to the third frames serve as the set up, which describes a story or a situation, and the fourth frame functions as the punch line. The criteria for humor stimuli were as follows: 1) To avoid the possibility of the participants having seen the cartoons, those selected had to be created sufficiently earlier. 2) The cartoons could not include any topical or technical contents that could cause misunderstanding.

\section{Measures}

On the basis of Nomura and Maruno (2008a), we prepared four items for the variable humor, four items for the variable comprehension, three items for the variable elaboration, and three items for the variable aversion (see Appendix A for details). Seven-point Likert scales (ranging from 1: completely disagree to 7: completely agree) were used to rate all these variables.

\section{Procedure}

Out of the 48 cartoons used in the study, six units were created by randomly aligning sets of 8 cartoons. Two units were combined in sequence as units 1 and 2, units 2 and 3, and so on. To counterbalance this, each series of combined cartoons had a normal and reverse sequence, resulting in 12 (6 types by 2 sequences) patterns of questionnaires.

The experimenters explained that individuals were free to decide whether or not they wished to participate, and distributed the questionnaires to high school and undergraduate students at the introduction to psychology class on open campus day and during psychology lectures. All the participants answered at their own pace in a group situation. In each case, the experimenter collected the questionnaires when all the participants had completed them.

\section{Data Analysis}

SPSS 18.0 and AMOS 18.0 were used for all analyses. In SEM analysis, we used the maximum likelihood (ML) estimate method to variance-covariance matrix calculated from row data. All responses to the various cartoons were used in the analyses. Since the same participant rated a series of cartoons, the data were so-called 3-phase (person * stimulus * items) data that were not independent of each other. Thus, there was a possibility of intercorrelation among responses from a single participant. However, given the fact that 3-phase data would influence the simple aversion model as well as the coactivation model, a relative comparison between the two models was possible. A response with missing values was removed from the analyses; as a result, the total number of responses was 7754 (3259 for high school and 4495 for undergraduate and graduate students).

First, we performed exploratory factor analyses with samples obtained from undergraduate and graduate students to examine whether or not the hypothesized pattern was found. Second, we tested the cross-validity of the coactivation model by focusing on whether or not the model can also be applied to samples obtained from high school student. Finally, to examine the theoretical prediction of the coactivation model, we tested the hypothesis that the weight of the path from aversiveness to humor in the model where the influence of elaboration is removed (partial regression coefficient) is lower than the weight (regression coefficient) in the simple aversion model. If this hypothesis is verified, the apparent influence from aversiveness to humor is due to the fact that elaboration influences both aversiveness and the humor experience.

\section{Results}

\section{Constructing the Coactivation Model}

Although factor analysis by using Maximum Likelihood method (oblimin with Kaiser normalization) using all the items indicated one item prepared for ease of understanding ("It was easy for me to anticipate the punch line as a punch line of a cartoon”) mainly loaded on the third factor contrary to theoretical assumption. After removing the item, factor analysis by using the same method was performed again. The results demonstrated a four-factor structure. Although the test of fit showed significant (chi-square $(32)=1463.27, p<.001$ ), this may due to a large number of samples in this study. As the structure matched with the hypothesized pattern while the factor about ease of understanding was negative, the factors were named humor, comprehension, elaboration, and aversion. The results are shown in Table 1.

Reliability (alpha) coefficients were calculated in order to examine the intra-consistency of each factor. The coefficients were .92 for humor, .80 for comprehension, .85 for elaboration, and .68 for aversion. The relatively lower coefficient of aversion may be due to the fact that the type of aversiveness in each cartoon differed. In addition, each cartoon reflected more than one aspect of discrimination, aggression, and sexuality. However, aversion was used for all subsequent analyses because any of its characteristics could have an influence.

The coactivation model was constructed using four factors (see Figure 2). Nomura and Maruno (2008a) postulated a covariance between the error variables of impression (the 3rd item of Humor, H3) and involvement (the 4th item of Humor, H4), which were observed variables of humor because these two variables would have similarity other than aspects of humor. Moreover, adding a theoretically-supported covariance maintains indices of fit and confirms the reliability of regression coefficients (Kano \& Azuma, 2003). Following these suggestions, the coactivation model was constructed with a covariance between impression (H3) and involvement (H4) in the present study (see Figure 3).

\section{Cross-Validity of Coactivation Model}

To examine whether or not the models also fit to samples obtained from high school students, we performed multiple 
Table 1.

Factor loadings and inter-factor correlations.

\begin{tabular}{|c|c|c|c|c|}
\hline \multicolumn{5}{|l|}{ Humor $(\alpha=.92)$} \\
\hline H2: Funniness & .96 & -.04 & -.06 & -.01 \\
\hline H1: Laughed/Nearly laughed & .96 & .03 & -.03 & .00 \\
\hline H3: Impression & .64 & -.08 & .14 & .05 \\
\hline H4: Involvement & .60 & -.05 & .25 & .05 \\
\hline \multicolumn{5}{|l|}{ Comprehension $(\alpha=.80)$} \\
\hline $\begin{array}{l}\text { C2: Meaning understanding of } \\
\text { punch line }\end{array}$ & .04 & -.98 & -.09 & -.03 \\
\hline $\begin{array}{l}\text { C1: Ease to aware what is } \\
\text { strange }\end{array}$ & .14 & -.87 & -.08 & -.04 \\
\hline $\begin{array}{l}\text { C3: Ease to anticipate a car- } \\
\text { toon punch line }\end{array}$ & -.07 & -.41 & .22 & .08 \\
\hline \multicolumn{5}{|l|}{ Elaboration $(\alpha=.85)$} \\
\hline E2: Association & .02 & .04 & .94 & -.03 \\
\hline E3: Memory recall & .06 & .02 & .79 & .02 \\
\hline E1: Anticipation & .09 & -.07 & .64 & .02 \\
\hline \multicolumn{5}{|l|}{ Aversion $(\alpha=.68)$} \\
\hline O3: Discriminative content & -.02 & .03 & -.05 & .84 \\
\hline O2: Aggressive content & .01 & -.02 & .08 & .59 \\
\hline O1: Sexual content & .02 & .00 & -.04 & .57 \\
\hline Inter-factor correlation & (1) & $(2)$ & (3) & (4) \\
\hline (1) Humor & - & -.54 & .52 & .22 \\
\hline (2) Comprehension & & - & -.37 & -.15 \\
\hline (3) Elaboration & & & - & .37 \\
\hline (4) Aversion & & & & - \\
\hline
\end{tabular}

Note: The extraction method was Maximum Likelihood method (oblimin with Kaiser normalization). Primary factor loadings are in boldface. $n=4495$

group SEM analysis. The criteria to be interpreted as good were more than .90 for goodness of fit index (GFI), adjusted goodness of fit index (AGFI), and comparative fit index (CFI), and less than .08 for root mean square error of approximation (RMSEA). Relatively smaller Akaike information criterion (AIC) and Browne-Cudeck criterion $(B C C)$ are better because they represent divergence from the ideal model. The results demonstrated that indices were good even when all parameter were rigorously constrained as the same between university and high school sample $(G F I=.931, A G F I=.917, C F I=.945$, RMSEA $=.056, A I C=3875.80, B C C=3858.04)$.

\section{Comparison between Regression Coefficient and Par- tial Regression Coefficient}

For confirmation, we checked that the simple aversion model also fitted to samples obtained from high school students as well as that from university students. The results showed good fit $(G F I=.973, A G F I=.962, C F I=.976, R M S E A=.049, A I C$ $=807.21, B C C=807.28)$. To examine whether or not an apparent effect of aversion disappears when the influence of elaboration is taken into account, the regression coefficient of the simple aversion model (see Figure 4) was compared with the partial regression coefficient of the coactivation model (see Figure 3). The result demonstrated that the regression coefficients were $.18(p<.05)$ for the simple aversion model and .03 (ns) for the coactivation model.

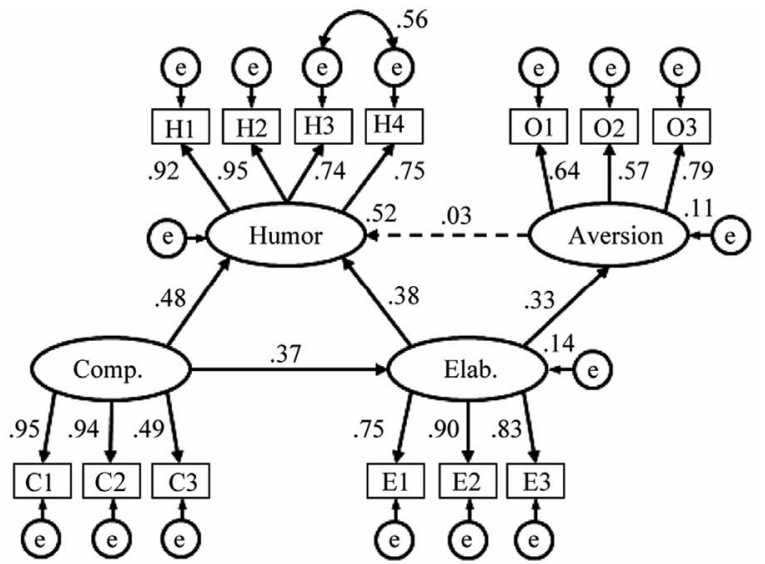

Figure 3.

The estimated coactivation model. All parameters in the figure are significant $(p<.01)$, except for the dashed arrow $(p>.05)$ from aversion to humor. The coefficients in the figure are standard estimates. Comp. $=$ Comprehension, Elab. $=$ Elaboration. $N=7754$.

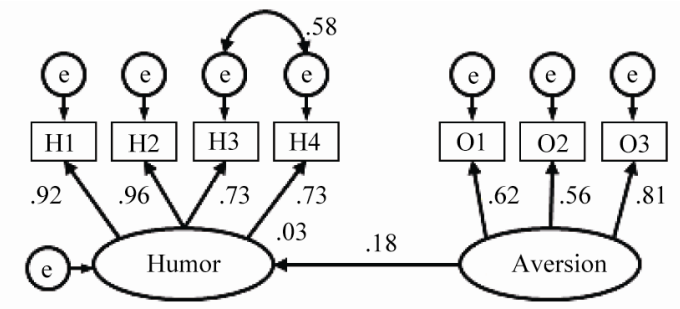

Figure 4.

The estimated simple aversion model. All parameters in the figure are significant $(p<.05)$. The coefficients in the figure are standard estimates. $N=7754$.

\section{Discussion}

\section{Factor Structure}

The results of factor analysis showed that ease of anticipating the punch line as a punch line of a cartoon loaded on comprehension while that as a daily happening did not. An existing study (Pollio \& Mers, 1974) pointed out that stimuli with high predictability of punch line were inclined to be rated as funnier than completely unpredictable ones. The results of factor analysis suggest that only predictability as a punch line of humor stimulus was an aspect of ease to comprehension that affects the elicited humor experience.

\section{Cross-Validity and Generalizability of the Activation Model}

The results of the simultaneous multiple group analysis showed that the model fit the data even all parameters were equal between the models with using samples obtained from high school and university students. This seemed to confirm the commonality of interrelationships between factors. The fit indices of the simple aversion model were greater than those of the coactivation model. However, the fact that the predictive power was very weak (only 3\%) indicated that the simple aversion model was not appropriate as a model for explaining the 
humor experience. On the other hand, the activation model explained humor to a large extent (approximately $50 \%$ of the total variance). It can be concluded that the model would represent common mechanisms for humor elicitation. Moreover, these results were obtained with various cartoons, each of which contained different topics, components, and logic flow (sentient or sentient-and-logical incongruity). Fit indices would be worse if humor was elicited in a different way than the hypothesis of the coactivation model, or if the humor elicitation process varied from one stimulus to another. Nevertheless, the results supported the coactivation model, indicating its generalizability.

\section{Theoretical Prediction of the Coactivation Model}

Consistent with the theoretical prediction, the apparent influence of the simple aversion model derived from the effect of elaboration. The central claim of the coactivation model is that the apparent influence from aversiveness to humor is observed not because aversiveness itself has power but because the third variable-elaboration-affects both humor experience and aversiveness. Moreover, the influence of aversiveness was very weak in the coactivation model. This suggests that conscious humor experience is mainly determined not by aversiveness but by ease of understanding and amount of elaboration. This point of view provides a possible solution to the existing complicated research about the effects of aversiveness on the humor experience. That is, by taking degree of elaboration into account, inconsistent results about the effect of aversiveness on humor experience can be explained. For instance, the inverted U-shaped relationship between aggression and humor experience pointed out by Zillmann et al. (1974) can be considered as follows. According to the coactivation model, modest aggression implied in humor stimuli is, as a result of elaboration, activated in one's mind along with the humor experience. Activated aggression must increase with an increase in elaboration, thereby leading to the apparent positive correlation between them. On the other hand, if the aggressive component is expressed more directly, there is no room left for elaboration. In this case, explicit and broad aggression is intrinsically involved in humor stimuli. The type of aggression is unrelated to elaboration. Therefore, the apparent correlation between aggression and humor experience will disappear. This explains the proportional relationship between aggression and humor experience, that is, the left side of the U-shaped relationship. In fact, a small portion of aversiveness was explained by elaboration (the coefficient was .33, explaining approximately $11 \%$ of aversion). This result suggests that to a great extent, aversiveness is affected by some component other than elaboration.

With regard to extreme aggression, however, it is difficult to argue in detail because the present study did not consider it. Nonetheless, when a humor stimulus involves extreme aggression, there is a possibility of a completely different process occurring, rather than the humor elicitation model proposed in this paper. Since extreme aggression sometimes threatens a person's sense of safety, individuals become anxious with an increase in aggression. At such a time, one's state of mind may change from paratelic, in which one enjoys the situation as play, to telic, wherein one makes an effort to ensure the safety of self or that of an in-group member (Apter, 1982; Nomura \& Maruno, 2008b). In such a case, no one enjoys the stimuli, result- ing in negative correlation between the degree of aggression and humor experience. This is definitely different from the process wherein the humor experience decreases because of a decline in elaboration, which is deduced from the coactivation model. Rather, in the given situation, humor elicitation itself is blocked by the processing of other information. In conclusion, the scope of the coactivation model is limited to situations where the mental and physical safety of an individual and their in-group members are not threatened by the aversiveness involved in a humor stimulus. The hypotheses deduced by the model fit naïve knowledge about jokes or cartoons, such as "It's not good to just put someone down" or "An implied sexual component is better." In future research, it is necessary to examine the hypotheses in order to confirm the applicability of the coactivation model.

\section{Future Direction}

In the future, studies on the coactivation model have to resolve the following problems.

First, although a series of studies using four-frame cartoons as humor stimuli showed that the model can be generalized with high reliability and validity, it is unclear whether the model can be applied to humor experiences elicited by other forms of stimuli, such as jokes or vaudeville performances. It is necessary to investigate whether or not the model can explain humor elicitation with other types of stimuli with sentient incongruity derived from gesture or melody.

Second, the cognitive process in recursive elaboration has to be explored in more detail. Since elaboration is an association or memory recall of an experience, neurological methods will be useful to investigate its essence. A study focusing on event-related potentials (ERPs) demonstrated that the ERP of participants who appreciate humor indicated relatively longlasting negative potential for 500 to 900 ms (Coulson \& Kutas, 2001). On the other hand, negative potential was not observed in the ERP of participants who did not appreciate humor. It is pointed out that a long-lasting potential represents retrieving a new frame from long-term memory to operate information in working memory (Coulson \& Kutas, 2001). The potential would relate to memory recall of one's experience as well as understanding of content meaning. In this sense, the endurance of the potential is a possible index of an individual's amount of elaboration.

Finally, time course of humor elicitation should be revealed by using accurate methods. The results of existing studies that support the arousal-boosting effect (Martin, 2007) are uncertain because an increase in arousal can be interpreted as the result of elaboration or humor experience per se as well as aversiveness. In other words, even if the humor experience is greater when arousal increases, it is not certain that the relationship arises from aversiveness, elaboration, or humor experience. The present study suggests that the apparent influence of aversiveness is a product of recursive elaboration. However, this study cannot reject arousal-boosting effect of aversiveness immediately. It is necessary to test the relationships between the coactivation model and the hypothesis of the arousal boosting effect by measuring arousal level, elaboration, and humor experience separately. For this kind of research, researcher should prepare devices to measure the components continuously like affect rating dial (Ruef \& Levenson, 2007). Hence, the focus of future 
research should be whether or not change of physiological indices precede humor experience and the relationship between aversiveness and arousal level is demonstrated even when the obtained data are adjusted by elaboration. The results of such research will provide sufficient proof that either facilitates the development of an arousal-boosting model or supports the coactivation model.

\section{References}

Apter, M. J. (1982). The experience of motivation: The theory of psychological reversals. New York, NY: Academic Press.

Averill, J. R. (1969). Autonomic response patterns during sadness and mirth. Psychophysiology, 5, 399-414. doi:10.1111/j.1469-8986.1969.tb02840.x

Cantor, J. R., Bryant, J., \& Zillmann, D. (1974). Enhancement of humor appreciation by transferred excitation. Journal of Personality and Social Psychology, 30, 812-821. doi:10.1037/h0037543

Chapman, A. J. (1973). An electromyographic study of apprehension about evaluation. Psychological Reports, 33, 811-814.

Coulson, S., \& Kutas, M. (2001). Getting it: Human event-related brain response to jokes in good and poor comprehenders. Neuroscience Letters, 316, 71-74. doi:10.1016/S0304-3940(01)02387-4

Cunningham, W. A., \& Derks, P. (2005). Humor appreciation and latency of comprehension. Humor: International Journal of Humor Research, 18, 389-403. doi:10.1515/humr.2005.18.4.389

Deckers, L. H. (1993). On the validity of a weight-judging paradigm for the study of humor. Humor: International Journal of Humor Research, 6, 43-56. doi:10.1515/humr.1993.6.1.43

Ferro-Luzzi, G. E. (1997). On unnecessary incongruities. Humor: International Journal of Humor Research, 10, 117-120.

Forabosco, G. (2008). Is the concept of incongruity still a useful construct for the advancement of uumor research? Lodz Papers in Pragmatics, 4, 45-62. doi:10.2478/v10016-008-0003-5

Gervais, M., \& Wilson, D. S. (2005). The evolution and functions of laughter and humor: A synthetic approach. The Quarterly Review of Biology, 80, 395-430. doi:10.1086/498281

Goldstein, J. H., Harman, J., McGhee, P. E., \& Karasik, R. (1975). Test of an information -processing model of humor: Physiological response changes during problem- and riddle-solving. Journal of General Psychology, 92, 59-68. doi:10.1080/00221309.1975.9711328

Hayashi, K., Hayashi, T., Iwanaga, S., Kawai, K., Ishii, H., Shoji, H., \& Murakami, K. (2003). Laughter lowered the increase in postprandial blood glucose. Diabetes Care, 26, 1651-1652. doi:10.2337/diacare.26.5.1651

Herzog, T. R., \& Anderson, M. R. (2000). Joke cruelty, emotional responsiveness and joke appreciation. Humor: International Journal of Humor Research, 13, 333-352. doi:10.1515/humr.2000.13.3.333

Herzog, T. R., Harris, A. C., Kropscott, L. S., \& Fuller, K. L. (2006). Joke cruelty and joke appreciation revisited. Humor: International Journal of Humor Research, 19, 139-156. doi:10.1515/HUMOR.2006.007

Hilson, T. R., \& Martin, R. A. (1994). What's so funny about that?: The domains-interaction approach as a model of incongruity and resolution in humor. Motivation and Emotion, 18, 1-29. doi:10.1007/BF02252473

Ito, H. (2007). The cognitive and emotional process through which one experiences humor: Toward an integration of two models in incongruity theories. Cognitive Studies: Bulletin of the Japanese Cognitive Science Society, 14, 118-132.
Johnson-Laird, P. N. (1980). Mental models in cognitive science. Cognitive Science, 4, 71-115. doi:10.1207/s15516709cog0401_4

Kano, Y., \& Azuma Y. (2003). Use of SEM programs to precisely measure scale reliability. In H. Yanai et al. (Eds.), New developments in psychometrics (pp. 141-148). Tokyo: Springer Verlag.

Koestler, A. (1964). The act of creation. New York, NY: Penguin Books.

Langevin, R., \& Day, H. I. (1972). Physiological correlation of humor. In J. H. Goldstein and P. E. McGhee (Eds.), The psychology of humor: Theoretical perspectives and empirical issues (pp. 129-142). New York, NY: Academic Press.

Lazarus, R. S. (1991). Emotion and adaptation. New York, NY: Oxford University Press.

Martin, R. A. (2007). The psychology of humor: An integrative approach. Burlington, MA: Elsevier Academic Press.

McCauley, C., Woods, K., Coolidge, C., \& Kulick, W. (1983). More aggressive cartoons are funnier. Journal of Personality and Social Psychology, 44, 817-823. doi:10.1037/0022-3514.44.4.817

Nerhardt, G. (1970). Humor and inclination to laugh: Emotional reactions to stimuli of different divergence from a range of expectancy. Scandinavian Journal of Psychology, 11, 185-195. doi:10.1111/j.1467-9450.1970.tb00734.x

Nomura, R., \& Maruno, S. (2008a). Modeling of a humor elicitation process in vaudeville settings. Cognitive Studies: Bulletin of the Japanese Cognitive Science Society, 15, 188-201.

Nomura, R., \& Maruno, S. (2008b). An integration of humor generation theories and a proposal of Dynamical Comprehension and Elaboration Theory. Japanese Psychological Review, 51, 500-525.

Pollio, H. R., \& Mers, R. W. (1974). Predictability and the appreciation of comedy. Bulletin of the Psychonomic Society, 4, 229-232.

Raskin, V. (1985). Semantic mechanisms of humor. Dordrecht: D. Reidel.

Ruch, W. (1993). Exhilaration and humor. In M. Lewis and J. M. Haviland (Eds)., Handbook of emotions (pp. 605-616). New York, NY: Gulford.

Ruch, W. (2008). Psychology of humor. In W. Ruch (Ed.), The primer of humor research (pp. 17-100). Berlin: Mouton de Gruyter. doi:10.1515/9783110198492.17

Ruef, A. M., \& Levenson, R. W. (2007). Continuous measurement of emotion. In J. A. Coan and Allen, J. J. B. (Eds.), Handbook of emotion elicitation and assessment (pp. 286-297). New York, NY: Oxford University Press Inc.

Schachter, S., \& Wheeler, L. (1962). Epinephrine, chlorpromazine, and amusement. Journal of Abnormal Social Psychology, 65, 121- 128. doi:10.1037/h0040391

Shultz, T. R. (1972). The role of incongruity and resolution in children's appreciation of cartoon humor. Journal of Experimental Child Psychology, 13, 456-477. doi:10.1016/0022-0965(72)90074-4

Suls, J. M. (1972). A two-stage model for the appreciation of jokes and cartoons. In J. H. Goldstein and P. E. McGhee (Eds.), The psychology of humor: Theoretical perspectives and empirical issues (pp. 81-100). New York, NY: Academic Press.

Wyer, R. S., \& Collins, J. E. (1992). A theory of humor elicitation. Psychological Review, 99, 663-688. doi:10.1037/0033-295X.99.4.663

Zillmann, D., Bryant, J., \& Cantor, J. R. (1974). Brutality of assault in political cartoons affecting humor appreciation. Journal of Research in Personality, 7, 334-345. doi:10.1016/0092-6566(74)90055-5

Zwaan, R. A., \& Rapp, D. N. (2006). Discourse comprehension. In M. A. Gernsbacher and M. J. Traxler (Eds.), Handbook of psychoinguiscs (pp. 725-764). San Diego, CA: Elsevier. doi:10.1016/B978-012369374-7/50019-5 


\section{Appendix}

The list of questions asked in the questionnaires. An * indicates that the item was removed as a result of the first factor analysis.

\section{Humor}

H1. I found the cartoon funny.

H2. I was inclined to laugh or laughed.

H3. The cartoon made an impression on me.

H4. I was drawn into the story.

\section{Aversion}

O1. I felt that the contents of the cartoon were discriminatory.

O2. I felt that the contents of the cartoon were aggressive.

O3. I felt that the contents of the cartoon were sexual.

\section{Comprehension}

C1. It was easy for me to understand the meaning of the punch line.

C2. It was easy for me to identify what is funny (strange).

C3. It was easy for me to anticipate the punch line as a punch line of a cartoon.

*C4. It was easy for me to anticipate the punch line as a daily happening.

\section{Elaboration}

E1. I thought about things that were relevant to the contents of the cartoon.

E2. I remembered some event relevant to the contents of the cartoon.

E3. I imagined some event that will happen after this scene. 